\title{
MATERNIDADE E O ABUSO SEXUAL INFANTIL INTRAFAMILIAR: GARANTIR UM COLO PROTETOR
}

\author{
MOTHERHOOD AND INTRAFAMILIAL CHILD SEXUAL ABUSE: \\ TO GUARANTEE A PROTECTIVE EMBRACE
}

\author{
Isabela Alves Mattos ${ }^{1}$ Isabel Maria Sampaio Oliveira Lima1
}

\begin{abstract}
RESUMO:
Diversas têm sido as mudanças relativas à condição feminina ao longo das últimas décadas. No entanto, no discurso dominante ainda persiste a função materna enquanto atribuição da mulher no cuidado e na proteção da prole. A mulher continua a ser encarada enquanto a grande responsável pelo equilíbrio familiar. Ao enfrentar a circunstância do abuso sexual intrafamiliar de um filho, a mãe poderá garantir um colo protetor à criança ou silenciar, em cumplicidade com o abusador. A possibilidade de vir a ser agente eficaz de proteção do filho confere à mãe a condição de reconfigurar as relações familiares ao dar limites e determinar prioridades de atenção. O presente artigo visa analisar a maternidade quando defrontada com casos de abuso sexual infantil intrafamiliar. Adotase na pesquisa uma estratégia qualitativa mediante revisão de literatura e revisão legislativa. A primeira foi realizada com levantamento de artigos científicos em periódicos observando-se palavras-chave relacionadas ao leque de possibilidades para apreensão do fenômeno. O resultado da revisão de literatura evidencia que variáveis sobre origem econômico-social da mãe pode influenciar sua reação. A revisão legislativa aponta a necessidade de superar a leitura da norma para a sua efetiva implementação. Observase, igualmente, que a concepção acerca da maternidade poderá alterar-se consoante determinada cultura, contexto histórico-social. A ocorrência de adversidades que atingem a sua prole enseja uma postura proativa, descolada da condição de administradora doméstica. Quando firme, o cuidado materno pode significar a proteção da integridade da criança.
\end{abstract}

Palavras-chave: maternidade; abuso sexual; proteção da criança; família.

Advogada. Membro do Grupo de Pesquisa Direitos Humanos, Direito à Saúde e Família (CNPq/UCSal).

2 Professora Adjunta. Programa de Pós-graduação em Família na Sociedade Contemporânea (PPGFSC) da Universidade Católica do Salvador (UCSal).

Corresponding author: isabelmsol@gmail.com

Suggested citation: Mattos IA, Lima IMSO. Motherhood and intrafamilial child sexual abuse: to guarantee a protective embrace. J. Hum. Growth Dev. 2012; 22(3): 373-377

Manuscript submitted Mar 02 2012, accepted for publication Sep 202012. 


\begin{abstract}
:
Many were the changes over the past decades regarding the status of women. However, the dominant discourse is still set on the maternal role as being the women's duty to care for, and protect, their offspring. Women are still seen as largely responsible for family balance. If a child faces intrafamilial sexual abuse, his mother may offer him a protective embrace, or fall silent, becoming the abuser's accomplice. That she may be the one effectively protecting her child gives the mother the ability to reconfigure family relationships as she sets limits and attention priorities to them. This article intends to analyze motherhood when confronted with cases of child sexual abuse within the family. A qualitative approach has been adopted, by means of literature and law reviews. The first survey was conducted using scientific articles in journals with an attention to keywords related to the possibilities of understanding the phenomenon. The conclusion on literature review shows that variables relative to the mothers' socio-economic roots may influence their reaction. The legislative review indicates the need to surpass the mere reading of regulations for their effective implementation. Moreover, it has been noted that the conception of motherhood may change depending on cultural or sociohistorical context. The occurrence of adversities affecting their offspring entails a proactive stance, distinct from the housewife status. When firm, motherly care can signify the protection of her child's welfare.
\end{abstract}

Key words: motherhood; sexual abuse; child protection; family.

\section{INTRODUÇÃO}

A maternidade confere à mulher uma nova condição, que enseja a redefinição do lugar que ocupa, ao vivenciar e desempenhar, no leque do seu feminino, a função de mãe ${ }^{1}$. Ao identificar-se, pois, neste papel culturalmente qualificado, a mulher cresce, diante de si e do significado que a sociedade se lhe atribui.

Esta experiência individual é intergeracional, assimila valores da cultura e requer determinadas atuações, práticas e responsabilizações que se projetam por um longo tempo de criação, pois envolve a prestação de assistência e a proteção que possibilitam o desenvolvimento físico e psicoemocional dos filhos.

A despeito de todas as transformações sociais sobrevindas nas últimas décadas, antigos discursos sociais prosseguiram no robustecimento do papel das mulheres na família enquanto mães e esposas. Nos dias atuais a figura materna ainda guarda o símbolo cultural e socialmente construído da personificação do amor e do afeto, consistindo na principal intermediadora de conflitos no $l a r^{2}$. Este papel, a ser desempenhado, sobretudo, nas hipóteses de adversidades relacionadas à prole, também deverá ser cumprido na ocorrência do abuso sexual intrafamiliar.

O abuso sexual infantil intrafamiliar é considerado um dos grandes males da sociedade contemporânea. Trata-se de um complexo problema de saúde pública que atinge crianças em todo mundo ${ }^{3}$, circunstância que demanda uma análise dos componentes familiares, além do papel da mãe, sua ausência ou eventual silêncio diante do problema.

A análise acerca da figura materna ganha especial relevância, uma vez que estudos apontam as mães como os atores adultos primordiais na proteção da sua prole, sendo também a resposta materna face ao abuso elencada como um dos fatores chaves na recuperação da criança ${ }^{4}$.

\section{Contextualizando a maternidade}

No decorrer do século XX, mudanças sociais, tecnológicas e econômicas favoreceram transformações nas configurações familiares brasileiras e nas expectativas e funções de seus membros ${ }^{5}$. Destaca-se o acesso mais fácil aos métodos contraceptivos como condi- 
ção que conferiu à mulher um maior domínio sobre o seu corpo e uma livre escolha da maternidade, permitindo escolhas, tal como a diminuição do número de filhos, sobretudo, nas classes médias e altas ${ }^{6}$. 0 crescimento da inserção feminina no mercado de trabalho das mulheres e a consequente ascensão ao papel de chefes de família ${ }^{6,7}$ constituíram, dentre outras, elementos de significativa mudança.

Para Wagner ${ }^{7}$ a entrada da mulher no mercado de trabalho acarretou diversas transformações nas relações entre os casais, favorecendo o declínio do poder e da superioridade masculina. A autora ressalta, entretanto, que na família contemporânea, por mais que seja observado um aumento da participação do pai no ambiente doméstico, persiste uma maior demanda para a mãe relativamente ao lar e aos filhos. Nessa direção, Azevedo e Arrais ${ }^{8}$ entendem que "há uma nova mulher, mas que vive sob o manto das velhas representações, pois continuamos cobrando delas o velho modelo de mãe idealizada" (p. 270).

Moreira e Rasera ${ }^{9}$ sugerem que os significados e os sentidos que as mulheres conferem ao fenômeno da maternidade nos dias atuais persistem amplamente influenciados pelas concepções de natureza sócio histórica. A maternidade é descrita, pelas participantes do estudo, como algo revestido de extrema beleza, amor, instinto, isto é, como um evento natural e divino, a ser vivenciado por todas as mulheres. Esta vertente de compreensão solidifica peculiares sentidos acerca do que é ou necessitaria ser a maternidade, instituindo formas e padrões para bem exercê-la que interferem nas práticas diárias das mães.

Os avanços legislativos acerca dos direitos da criança, contidos no Estatuto da Criança e do Adolescente, promovem o surgimento de políticas que afirmam a responsabilidade materna na criação de filhos saudáveis e equilibrados, independentemente das condições e problemas por ela enfrentados ${ }^{10}$.

Em algumas situações, contudo, a instituição familiar não consegue bem desempenhar a função de proteção dos seus membros atribuída legalmente, a exemplo das situações de violência, como abuso sexual de crianças, quando ocorre uma quebra nos limites internos das relações familiares.

\section{O desafio do abuso sexual infantil intrafamiliar e a maternidade}

Entende-se o abuso sexual como uma espécie de violência que envolve a prática de qualquer ato de natureza sexual entre uma criança ou adolescente com pessoa que possui um estágio psicossexual mais avançado, sendo a vítima utilizada pelo perpetrador para a sua gratificação ou estimulação sexual ${ }^{11}$.

Os atos que caracterizam o abuso sexual podem variar desde a manipulação da genitália, carícias, voyeurismo, exibicionismo, bem como o ato sexual, com ou sem penetração ${ }^{12}$. No que concerne ao contexto da prática do abuso sexual, este poderá ocorrer tanto no ambiente familiar, como fora deste $\mathrm{e}^{11,13}$.

O abuso sexual extrafamiliar envolve, na maioria das vezes, pessoas desconhecidas das vítimas. Já o abuso sexual intrafamiliar é perpetrado, em muitos dos casos, por pessoas próximas à criança e que deveriam exercer o papel de cuidador ${ }^{14}$.

A utilização, pelo agressor, da proximidade e do vínculo que possui com a criança para cometer tal violência, desencadeia graves problemas de ordem social, emocional e cognitiva, os quais, consoante a literatura especializada, podem se manifestar nas vítimas a curto ou longo prazo. Dentre as possíveis consequências provocadas destacam-se os transtornos psicológicos de humor, ansiedade, alterações alimentares, hiperatividade, déficit de atenção e transtorno de estresse pós-traumático ${ }^{15}$.

Furniss ${ }^{16}$ elucida que as consequências psicológicas provocadas na criança encontram-se relacionadas a sete fatores, quais sejam: idade do início do abuso; a duração do abuso; grau de violência ou ameaça de violência; a diferença de idade entre a pessoa que cometeu o abuso e a criança que sofreu o abuso; os quão estreitos estavam relacionados o agressor e a criança; a ausência de figuras parentais protetoras; grau do segredo envolvido entre o adulto e a vítima.

Aponta a literatura que nos casos de abuso sexual infantil intrafamiliar, os principais agressores são os pais e padrastos. Há estudos que evidenciam tendência convergente no tocante aos principais abusadores. Baptista ${ }^{17}$, em pesquisa realizada através de uma análise documental registrada pelo Programa Sentinela na cidade de Campina Grande no período de janeiro de 2005 a dezembro de 2006, verificou que dos 27 casos de abuso intrafamiliares, os principais agressores foram o padrasto $(33,3 \%)$ e o pai, compondo $(29,7 \%)$ das notificações.

Nas famílias em que o abuso sexual de crianças ocorre, "as mães geralmente têm o papel do progenitor não abusivo. Nesse pa- 
pel a função protetora é crucial no abuso sexual prolongado" (p. 53) ${ }^{16}$. A análise acerca da figura materna ganha especial relevância, uma vez que, no contexto de abuso sexual, as mães são compreendidas enquanto os atores adultos primordiais na proteção da sua prole, sendo também a resposta materna face ao abuso elencada como um dos fatores chave na recuperação da criança ${ }^{4}$. Diante dessa concepção, mesmo diante da ausência de um suporte social ou legal, ainda assim, "as mães são valoradas conforme se aproximam ou não desse ideal de cuidado associado à maternidade" (p. 574) $)^{18}$.

Estudos apontam que a despeito da atribuição social e legal à figura materna do equilíbrio familiar e intermediação de conflitos, esta poderá esboçar diversas reações em face ao conhecimento do abuso sexual praticado contra sua prole. Algumas pesquisas mostram a figura materna enquanto participantes ativas no contexto do abuso sexual, atuando como cúmplices ou facilitadoras da violência ${ }^{19}$. Nessas circunstâncias elas são apontadas como negligentes e permissivas, deixando assim de exercer a função de cuidado e proteção dos filhos.

No cenário apresentado a mãe se mostra uma figura presente nas situações de abuso sexual, o que sugere o conhecimento da violência por ela, que acaba por constituir "um conluio perverso com o pai" (p. 169) ${ }^{20}$, passando a apoiar o agressor, permanecendo em silêncio. Em muitos desses casos a mãe, pela condição de dependência financeira e emocional do agressor, acaba por ser forçada a participar das práticas abusivas, situação em que a filha passa a ocupar o lugar até então atribuído à mãe dentro do contexto familiar, exercendo a função sexual ${ }^{21}$.

Ao tomar conhecimento do abuso, a mãe poderá adotar, contudo, uma atitude socialmente esperada, de cuidado e proteção. Tal conduta poderá acontecer através do oferecimento da denúncia do ato criminoso, uma vez que ela propicia a intervenção da esfera pública no ambiente privado, no próprio lar, elemento que favorece o afastamento do abusador e a inclusão da vítima em algum programa de tratamento.

Acerca da iniciativa de proteção através da denúncia do agressor, aporta um estudo realizado a partir da análise de processos de casos de violência que foram ajuizados pelas Promotorias Especializadas na Infância e Juventude no município de Porto Alegre no período de 1992 a $1998^{11}$. Na análise de 71 expedientes observou-se que a denúncia da violência sexual foi feita pela mãe em 37,6\% dos casos, em $29 \%$ a própria vítima ofereceu a denúncia, em $15,1 \%$ outros parentes, e em $6,5 \%$ a denúncia foi feita por instituições, como escolas, hospitais, verificando-se o diligente papel materno.

Em sentido diverso, a pesquisa realizada por Martins e Jorge ${ }^{3}$ - em análise dos prontuários sobre os casos notificados de abuso sexual no município de Londrina no ano de 2006 -, verificou que das 186 notificações realizadas, $67,2 \%$ foi feita principalmente por pessoas da família, como tios, irmãos, cunhados e primos, a mãe aparece na pequena porcentagem de $8,1 \%$ dentre os denun-ciantes, seguida de diretor de escola, pai e profissionais da saúde.

Em estudo realizado por Pires Filho ${ }^{21}$ (2009) na Região Metropolitana de Recife, mediante entrevistas semiestru-turadas com sete psicólogas inseridas em instituições que prestam atendimento às crianças vítimas de abuso sexual, quatro participantes apontaram a mãe, exclusivamente, como a pessoa que mais realiza a denúncia, permitindo que o abusador seja afastado do ambiente familiar. $\mathrm{O}$ estudo traz, igualmente, o olhar das participantes acerca das dificuldades enfrentadas pelas famílias. Estas, ao realizar a denúncia, deparam-se com o problema de sobrevivência, pois, em muitos casos, a figura do abusador também integra a do próprio provedor da casa. Esclarece o autor, contudo, que em alguns casos o abusador encontra a proteção da família, que nega a violência por diversas motivações, dentre elas, em razão da percepção deste como uma pessoa doente que necessita de cuidados.

A literatura destaca o fato de que a denúncia consiste em uma iniciativa muitas vezes difícil de ser tomada, tanto pela mãe, como pelos demais membros da família. A notícia do ocorrido junto ao órgão competente poderá não ocorrer no primeiro momento em que o adulto toma conhecimento do abuso sexual. Este elemento, identificado em pesquisas supra referidas, aponta a dificuldade da mãe em oferecer a denúncia e quebrar com o ciclo de violência.

Nesse sentido, a pesquisa realizada por meio da análise de processos denunciados nos anos de 1992 a 1998 no Município de Porto Alegre ${ }^{11}$, identificou que dos 71 expedientes identificados, em $61,7 \%$ dos casos alguma pessoa relatou já ter conhecimento da violência sem ter oferecido a denúncia. Destes casos, dentre as pessoas que já tinham conhecimento anterior da situação abusiva $55,2 \%$ eram a mãe, $54,3 \%$ os irmãos e $10,3 \%$ outras pessoas que não faziam par- 
te do contexto familiar, dados que demonstram a dificuldade não só da família, mas também da sociedade em denunciar as suspeitas ou constatação de abuso sexual.

Acerca da dificuldade materna em adotar um papel de cuidado e proteção, tal como o oferecimento da denúncia, estudos realizados indicam que embora a grande parcela das mães confiasse, ao menos em parte, no relato da criança, "algumas não conseguiam emitir respostas de apoio e proteção, evidenciando ambivalência ou inconsistência" ( $p$. 86-87) ${ }^{22}$. Esta circunstância de conferir pouca credibilidade ao relato infantil demonstra não existir uma constante entre as mães que acreditam nas revelações dos filhos enquanto mães protetoras ou não. Acreditar no relato não implica, pois, em uma atitude diligente. Pode ocorrer, inclusive, o silêncio e a conivência. Entende-se a proteção como um papel proativo que gere segurança para a vítima e imediata interrupção da prática abusiva.

Elementos outros, tais como "a percepção do papel de ser mãe" (p. 91)22 e algumas concepções e aspectos que guardam relação com a maternidade, podem influenciar nas respostas maternas. Quando a mãe age e não reconhece o abuso, busca manter o aparente equilíbrio e segurança familiar, "pois revelálo representaria reconhecer o fracasso de seu papel como mãe e esposa" (p. 251) ${ }^{3}$.

A condição de inferioridade a que muitas mulheres se colocam na relação conjugal, também acaba por propiciar atitudes abusivas, quando "as próprias mulheres delegam poderes a seus maridos, companhei-

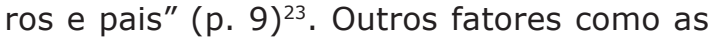
ameaças, o medo de perder a família, ou ainda por questões de dependência financeira do abusador acabam por não propiciar o oferecimento da denúncia por parte da mãe.

A literatura ressalta que outros elementos favorecem o temor materno para realizar denúncia. Dentre estes, o receio de que o rompimento com as pessoas da família e conhecidos possa dificultar a atitude materna.
O temor em relação à vida futura, uma vez que terá de enfrentá-la sem o ajuda de seu marido ou companheiro, que muita das vezes é o abusador, se soma aos demais, podendo dificultar a reação da mãe.

Em um estudo realizado por Santos e Dell'Aglio ${ }^{22}$ foram entrevistadas 10 mães de meninas sexualmente abusadas que estavam sendo atendidas em um programa de um hospital público do Município de Porto Alegre, sendo que em oito casos, dos dez analisados, a mãe foi a primeira pessoa a tomar conhecimento sobre o abuso. O que para as autoras demonstra a importância da mãe, não somente enquanto pessoa a quem se relata a violência, "mas também para oferecer apoio e poder auxiliar a vítima a lidar com as repercussões do abuso" (p. 89).

Foi observado no estudo que as respostas das mães no tocante à notícia do abuso sexual praticado contra suas filhas se localizavam em duas dimensões somente: a da credibilidade e a da ação. Estando a dimensão da credibilidade ligada ao crédito ou descrédito no relato do abuso sexual pelos fiIhos, já a dimensão da ação enquanto aquela onde relaciona a iniciativa ou não de denunciar. Chegando à conclusão de que não existe uma direta relação entre o crédito no relato da criança e a tomada de uma atitude protetiva como o afastamento do abusador ou a denúncia.

Assim, nas análises de pesquisas demonstram não haver uma conduta uniforme das mães quando se trata dessa espécie de violência. Estas poderão figurar enquanto partícipes ou perpetradoras dos abusos, podendo a sua conduta em outros casos vir a ser diligente, circunstância que favorecerá o rompimento do ciclo de violência. Ressalta-se a importância da criação de programas de auxílio visando amparar as mães e conferir suporte financeiro para que possam, com autonomia, realizar e prosseguir com a denúncia de modo a Ihes conferir a força protecional diante da "minha filha", enquanto ser que merece e demanda o colo materno e sua voz ativa. 


\section{REFERÊNCIAS}

1. Dias AC, Lopes R. Representações de maternidade de mães jovens e suas mães. Psicol estud 2003; 8(1): 63-73.

2. Serpa MG. Perspectivas sobre papéis de gênero masculino e feminino: um relato de experiência com mães de meninas vitimizadas. Psicol Soc 2010; 22(1): 14-22.

3. Martins $\mathrm{CB}$, Jorge $\mathrm{MH}$. Abuso sexual na infância e adolescência: perfil das vítimas e agressores em município do sul do Brasil. Texto contextoenferm 2010; 19(2): 246-255.

4. Hooper CA. Madres sobrevivientes al abuso sexual de sus niños. Nueva Visión: Buenos Aires; 1994.

5. Rabinovich E, Moreira L, Franco A. Papéis, Comportamentos, Atividades e Relações entre os Membros da Família Baiana. (no prelo).

6. Scavone L. Dar a vida e cuidar da vida: feminismo e ciências sociais. São Paulo: Ed. UNESP; 2004.

7. Wagner A et al. Compartilhar tarefas? Papéis e funções de pai e mãe na família contemporânea. Psic: Teor e Pesq 2005; 21(2): 181-186.

8. Azevedo KR, Arrais A. O mito da mãe exclusiva e seu impacto na depressão pós-parto. Psicologia: Reflexão e Crítica 2006; 19(2): 269-276.

9. Moreira RL, Rasera E. Maternidades: os repertórios interpretativos utilizados para descrevê-las. Psicol Soc 2010; 22(3): 529-537.

10. Meyer DE. A politização contemporânea da maternidade: construindo um argumento. Revista de Gênero 2006; 6(1): 81-104.

11. Habigzang LF et. al. Abuso sexual infantil e dinâmica familiar: aspectos observados em processos jurídicos. Psic: Teor e Pesq 2005; 21(3): 341-348.

12. Pfeiffer $L$, Salvagni E. Visão atual do abuso sexual na infância e adolescência. J Pediatr (Rio J.) 2005; 81(5 Supl): S197-S204.
13. Faleiros E, Campos J. Repensando os conceitos de violência, abuso e exploração sexual de crianças e adolescentes. Brasília: UNICEF; 2000.

14. Santos SS, Dell'Aglio D. Compreendendo as mães de crianças vítimas de abuso sexual: ciclos de violência. Estud psicol (Campinas) 2008; 25(4): 595-606.

15. Habigzang LF et al. Grupoterapia cognitivo-comportamental para meninas vítimas de abuso sexual: descrição de um modelo de intervenção. Psicol clin 2006; 18(2): 163-182.

16. Furniss T. Abuso sexual da criança: uma abordagem multidisciplinar. Porto Alegre: Artes Médicas; 1993.

17. Baptista RS et al. Caracterização do abuso sexual em crianças e adolescentes notificado em um Programa Sentinela. Acta paul enferm 2008; 21(4): 602-608.

18. Moreira LE, Nardi HC. Mãe é tudo igual? Enunciados produzindo maternidade(s) contemporânea(s). Rev Estud Fem 2009; 17(2): 569594.

19. Quiroz MI, Peñaranda FC. Significados y respuestas de las madres al abuso sexual de sus hijas(os). Rev latinoam cienc soc niñez juv 2009; 7(2): 1027-1053.

20. Dias MB. Incesto e o Mito da Família Feliz. In: Dias MB, organizadora. Incesto e alienação parental: realidades que a justiça insiste em não ver. São Paulo: RT; 2010. p. 153-184.

21. Pires Filho MF. Abuso sexual em meninos: a violência intrafamiliar através do olhar do psicólogo que atende em instituições. Curitiba: Juruá; 2009.

22. Santos SS, Dell'Aglio D. Revelação do abuso sexual infantil: reações maternas. Psic: Teor e Pesq 2009; 25(1): 85-92.

23. Araújo MF. Violência e abuso sexual na família. Psicol estud 2002; 7(2): 3-11. 